\section{The influence of birth order and situational stress on motor performance*}

\author{
DANIEL M. LANDERS \\ State University of New York, College at Brockport \\ Brockport, N.Y. 14420 \\ and \\ RAINER MARTENS \\ Children's Research Center, University of Illinois, Urbana-Champaign \\ Champaign, Ill. 61820
}

Schachter's hypothesis that first-borns are more vulnerable than later-borns to the interfering effects of stress was experimentally tested by comparing the tracking performance of 50 first-born and 72 later-born Ss exposed to a low, moderate, or high threat of physical-harm condition. Questionnaire responses of Ss' perceived stress and Ss' heart rates indicated that two levels (high and low) of stress were successfully created. The performance results suggest that under moderate- and high-stress conditions first-borns perform more poorly than later-borns on early performance trials, particularly on the second trial under high stress.

Schachter (1959) has recently rekindled interest in birth-order research by finding first-born Ss to be more aroused by threats of electric shock than are later-born Ss. The greater reaction to stress of first-borns as compared to later-borns is believed to be a result of their inconsistent nurturance, which leads to dependency behavior in the form of affilitative responses (Schachter, 1959). Recent evidence (Jacoby, 1968 ) indicates that arousal differences between first- and later-born Ss are due to experimentally induced anxiety rather than to preexperimental differences in anxiety. Of the various types of stressors, Nisbett (1968) maintains that birth-order effects are particularly pronounced when Ss are subjected to threat of physical harm.

Although many investigators have examined volunteering rates and affiliative preferences of first- and later-borns for various situational stressors, a paucity of evidence exists concerning the effects of birth order on task performance. Innes \& Sambrooks (1969) examined Ss learning paired associates alone or while coacting with others. Their results indicate that first-born males tended to perform better than laterborn males while in a coacting condition, thus providing some support to

\footnotetext{
*This investigation was supported in part by a research grant to the Motor Performance and Play Research Laboratory via the Adler Zone Center by the Department of Mental Health of the State of Illinois and by U.S. Public Health Research Grant No. MH-07346 from the National Institute of Mental Health. Appreciation is extended to Drs. G. Roberts and G. Olafson for assistance in administering the CMAS.
}

Schachter's (1959) affiliation hypothesis. The effect of varying levels of stress on motor performance of first- and later-born Ss tested alone has not yet been experimentally tested. According to Schachter, the performance of first- and later-borns should interact with the inverted-U hypothesis between stress and performance. Based on the inverted- $U$ hypothesis, performance increases as stress is increased up to a certain point, after which additional increases in stress results in inferior performance, particularly for Ss who are especially vulnerable to the interfering effects of stress (e.g., first-borns).

The evidnnce concerning birth-order differences in performance under high-stress situations has been equivocal. Later-borns have been found to be more effective (Torrence, reported by Schachter, 1959; Helmreich, 1966) and less vulnerable to stress (Nisbett, 1968; Weiss, 1967) than first-borns. Other evidence, however, has failed to show birth-order differences in performance under stress (Sharan, Amir, \& Kovarsky, 1969) and in vulnerability to stress (Vernon, 1967; Weller, 1964). The equivocal findings are not surprising, since the nonmonotonic relationship between stress and performance has only been implied from field studies and has not been tested under controlled experimental conditions. The failure to provide any corroborative evidence, other than performance responses, of the successful manipulation of stress is also a weakness of the above studies-particularly where negative results were obtained. The present study, therefore, determined the effect of birth order on novel motor task performance under three levels of physical harm stress. Heart rates and a self-report measure of perceived nervousness were used to corroborate the creation of stress. It was hypothesized that first-borns perform more poorly than later-borns when tested alone under conditions of high stress.

\section{SUBJECTS AND DESIGNS}

Initial birth-order information as well as Children's Manifest Anxiety Scores (CMAS) were obtained from 1,075 junior high school males. Fifty first- and only-borns and 72 later-borns who had scored in the upper decile, at the mean, and at the lower decile on the CMAS were selected as Ss. Ss from each group were then randomly assigned to a low-, moderate-, or high-stress treatment condition. A 2 by 3 factorial design, with two levels of birth order and three levels of stress, was used. The number of first-borns in the low-, moderate-, and high-stress conditions were 21,15 , and 14 , while the number of later-borns were 19,26 , and 27 , respectively.

TASK AND APPARATUS

The task consisted of tracking horizontally along a 52-in. curved piece of $3 / 4-i n$. aluminum tubing firmly mounted on a wooden base. The aluminum ring, which encircled the tubing and was used for tracking, was 1-1/8 in. in diam and was attached to a wooden handle. S's task was to hold the end of the handle with his dominant hand and move the ring continuously, and at his own pace, along the tube without touching the inside edge of the ring to the aluminum tubing. Each time the ring touched the aluminum tubing it completed an electric circuit which recorded on a Fairchild Universal Counter-Timer.

\section{PROCEDURE}

Approximately 2 months after the initial testing, physical education instructors told Ss that they had been selected randomly from class rosters to participate in a motor learning experiment. Two Es, who were not actively involved in the administration of the CMAS, tested the Ss. Prior to their participation in physical education, three Ss at a time were brought to the testing site by an $E$, seated, and then told to relax for approximately $15 \mathrm{~min}$. During the rest period and while $S$ was seated, two 60-sec heart rates (HRs) were recorded for each $S$. Each $S$ was then individually taken to an adjoining room and was introduced to a second $E$ who explained and demonstrated the experimental task and operations of the counter to $S$. E then proceeded to administer the experimental treatments. 


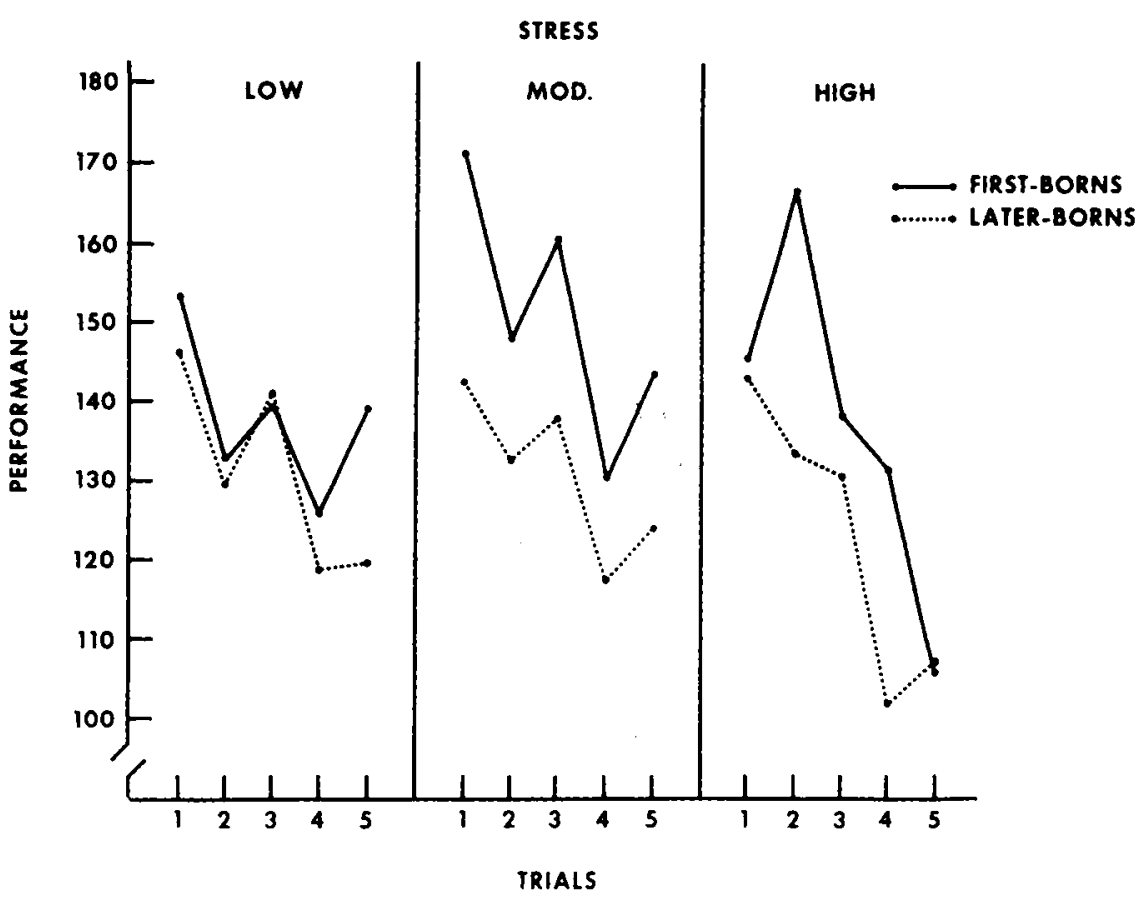

Fig. 1. Birth Order by Stress by Performance Trials interaction.

The Ss in the low stress condition were merely told that the purpose of the study was to see how well boys could do on the task and that they were to try their best. In addition, Ss in the moderate stress condition were told that if their accumulative scores for all five trials were above an unrevealed criterion score, they would receive a "slight electric shock" at the end of the experiment. Ss in the high stress condition were introduced to $\mathrm{E}$, who was wearing a white lab coat, and were told that he was a doctor. Ss were told that if their scores were above the unrevealed criterion, they would receive a "painful electric shock." Two electrodes, which were connected to an awesome-looking device labeled "for administering shock," were attached to S's forehead.

Prior to the first trial and after Trials 3 and $5, S$ was seated and three additional $60-\mathrm{sec}$ HRs were taken. In addition, a questionnaire response of S's perceived nervousness was taken after Trial 3. The rest period between the other trials was approximately 15 sec.

\section{RESULTS}

A Birth Order by Stress (2 by 3) ANOVA on S's perceived nervousness during the experiment showed that only the stress effect was significant $(\mathrm{F}=6.87, \quad \mathrm{df}=2 / 116, \quad \mathrm{p}<.01) . \quad \mathrm{A}$ Newman-Keuls test showed that Ss in the high-stress condition $(\overline{\mathrm{X}}=4.94)$ indicated significantly greater nervousness than $S s$ in the moderate$(\bar{X}=3.93)$ and low-stress $(\bar{X}=3.41)$ conditions, but the latter two groups were not significantly different.

A Birth Order by Stress by HR ( 2 by 3 by 3 ) ANOVA on the sequence of $H R$ discrepancies from the average of the two basal HRs showed a significant stress effect ( $F=3.94$, df $=2 / 116, p<.05)$. A Newman-Keuls test revealed that $S s$ in the high-stress condition had an increase in HR from basal $(\bar{X}=2.71)$, while $S s$ in the low-stress condition decreased $(\bar{X}=-2.61)$. The differences between the moderate $(\bar{X}=0.98)$ and high- and low-stress conditions were not significant.

The main effect for the sequence of the three HRs from basals was significant $(F=7.94, \quad d f=2 / 232$, $\mathrm{p}<.01$ ), but this was superseded by a significant Birth Order by HR interaction $(F=5.69, \quad \mathrm{df}=2 / 232$, $\mathrm{p}<.01)$. Post hoc tests indicated that only the HR taken after Trial 5 differed significantly ( $F=22.48$, $\mathrm{df}=2 / 232, \mathrm{p}<.01$ ), with later-borns showing a greater positive increase $(\bar{X}=2.46)$ from basal HRs than first-borns $(\overline{\mathrm{X}}=-0.56)$.

Performance Scores

A Birth Order by Stress by Trials ( 2 by 3 by 5 ) ANOVA on performance scores showed that the later-borns were slightly better than first-borns $(\mathrm{F}=2.88$, df $=1 / 116, \mathrm{p}<.09)$. The stress main effect and the Birth Order by Stress interaction were nonsignificant. The trials main effect was significant $(F=19.49, d f=4 / 464$, $\mathrm{p}<.01$ ), which indicated that $\mathrm{Ss}$ learned and reduced errors over the five performance trials. In addition to the trials effect, a significant Stress by Trials interaction $(F=2.17$, $\mathrm{df}=4 / 464, p<.05$ ) and Birth Order by Stress by Trials interaction $(F=1.89, \mathrm{df}=8 / 464, p<.06)$ were also significant. Inspection of the three-way interaction (see Fig. 1) shows that first-borns tended to perform worse than later-borns, particularly under moderate- and high-stress conditions. Whereas later-borns in all stress conditions reduced errors from Trial 1 to Trial 2 , first-borns in the high-stress condition increased errors from Trial 1 to Trial 2.

\section{DISCUSSION}

Inspection of Fig. 1 indicates that compared to that in the low- and high-stress groups, $S s$ in the moderate-stress condition had poorer performance (on the early trials) rather than better performance as would be predicted by the inverted-U hypothesis. To test the inverted-U hypothesis properly it is necessary to create at least three distinct and widely separate points along the stress continuum. HR and perceived nervousness results indicated that the high-stress condition differed significantly only from the low-stress condition. The failure to clearly distinguish three separate levels of stress could have accounted for the unexpected inferior performance of Ss in the moderate-stress conditiun. The successful creation of two levels of stress, however, was sufficient to test the birth-order hypothesis of the present study.

The results indicate that when threat of electric shock is introduced, as in the moderate- and high-stress conditions, first-borns experience performance decrements while later-borns' performance remains stable or improves, as in the last two trials under high stress. The major difference between $S s$ in the high-stress condition, as compared to Ss in the other stress conditions was that first-borns' performance deteriorated from Trial 1 to Trial 2, but first- as well as later-borns' poorer performance on early trials in the moderate and high-stress conditions supports the findings of Torrence and Helmreich. Only on the last performance trial under high stress did the first-borns perform at the same level as later-borns. This improvement in performance of first-borns and their having lower HRs than later-borns in the latter trials indicates that first-borns' vulnerability to stress may dissipate with increasing practice.

First-borns' decrease in performance on the second trial under high stress may be a result of the E-S interaction. Studies (Hilton, 1967; Rothbart, 1971 ) investigating mothers' 
interactions with their first- and later-born children while performing various tasks support first-born Ss' expectation for more precise qualitative feedback in the form of more complex technical explanations (Rothbart, 1971), task-oriented suggestions, and direct help (Hilton, 1967). If, as Schachter maintains, first-borns are more dependent on adults than are later-borns, feedback given by an adult $E$ without any indication as to the quality of the score in terms of the shock criterion, may have affected first-borns' decline in performance on the second trial in the high-stress condition.

J A C OBY, $\begin{gathered}\text { REFERENCES } \\ \text { Birth rank and }\end{gathered}$ pre-experimental anxiety. Joumal of Social Psychology, 1968, 76, 9-11.

HELMREICH, $R$. L. Prolonged stress in Sealab II: A field study of individual and group reactions. Doctoral dissertation, Yale University, 1966.

HILTON, I. Differences in the behavior of mothers toward first- and later-borm children. Journal of Personality \& Social Psychology, 1967, 7, 282-290.

INNES, J. M.. \& SAMBROOKS, J. Paired-associate learning as influenced by birth order and the presence of others. Psychonomic Science, 1969, 16, 109-110.

NISBETT, R. E. Birth order and participation in dangerous sports. Journal of Personality \& Social Psychology, 1968 , $8,351-353$.

ROTHBART, $M$. K. Birth order and mother-child interaction in an achievement situation. Journal of Personality \& Social Psychology, 1971. 17, 113-120.

SCHACHTER, S. The psychology of affiliation. Stanford, Calif: Stanford
University Press, 1959

SHARAN, S, AMIR, Y, \& KOVARSKY, $Y$. Birth order and level of task performance: A cross-cultural comparison. Journal of Social Psychology, 1969, 78, $157-163$.

VERNON, D. T. A., FOLEY, J. M., \& SCHULMAN, J. L. Effect of mother-child separation and birth order on young children's responses to two potentially stressful experiences. Journal of Personality \& Social Psychology, 1967, 5, $162-174$.

WEISS, J. H. Birth order and physiological stress response. American Psychologist. $1967,22,557$.

WELLER, L. The relationship of birth order to anxiety. Sociometry, 1962, 25, 415-417.

\section{CURRENT LITERATURE ON PERFORMANCE}

ATWOOD, R. W. (Brigham Young University, Provo, Utah 84601), \& HOWELL, R. J. Pupillometric and personality test score differences of female aggressing pedophiliacs and normals. Psychonomic Science, $1971,22,115-116$.

BLUM, G. S. (University of California, Santa Barbara, Calif. 93106), \& WOHL, B. M. Monetary, affective, and intrinsic incentives in choice reaction time. Psychonomic Science, 1971, 22, 69-70.

CRAFT, J. L. (University of Iowa, Iowa City, Iowa 52240), \& HINRICHS, J. V. Short-term retention of simple motor responses: Similarity of prior and succeeding responses. Journal of Experimental Psychology, 1971, 87, 297-302.

DOLL, T. J. (State University of New York at Stony Brook, Stony Brook, N.Y. 11790). Motivation, reaction time, and the contents of active verbal memory. Journal of Experimental Psychology, 1971, 87, 29-36.

FUCHS, A. H. (Bowdoin College, Brunswick, Maine 04011). Response latency and serial position in short-term memory. Psychonomic Science, 1971, 22, 75-76.

GEFFEN, G. (Monash University, Clayton, Victoria 3168, Australia), BRADSHAW, J. L., \& WALLACE, $G$. Interhemispheric effects on reaction time to verbal and nonverbal visual stimuli. Journal of Experimental Psychology, 1971, 87, 415-422.

LEVIS, D. J. (University of lowa, Iowa City, Iowa 52240). Effects of serial CS presentation on a finger-withdrawal avoidance response to shock. Journal of Experimental Psychology, 1971, 87, 71-77.

MARTINEZ, F. (Institut de Neurophysiologie et Psychophysiologie, Centre National de la Recherche Scientifique, Marseille, France). Comparison of two types of tactile exploration in a task of mirror-image recognition. Psychonomic Science, 1971, 22, 124-125.

PHILLIPS, W. A. (Experimental Psychology Laboratory, University of Sussex, Brighton BN1 9QY, Sussex, England). Reaction time and short-term visual memory.
Psychonomic Science, 1971, 22, 73-74.

SLAYTON, A. J. (University of South Carolina, Columbia, S.C. 29208), \& BLACK, R. W. Effects of knowledge of results and amount of stimulus change on "resistance to extinction" on a perceptual motor task. Psychonomic Science, 1971, 22, 111-112.

SMOTHERGILL, D. W. (Syracuse University, Syracuse, N.Y. 13210), MARTIN, R., \& PICK, H. L., JR. Perceptual-motor performance under rotation of the central field. Journal of Experimental Psychology, 1971, 87, 64-70.

THORNTON, J. W. (Angelo State University, San Angelo, Tex. 76901), \& JACOBS, P. D. Learned Helplessness in human subjects. Journal of Experimental Psychology, 1971, 87, 367-372.

WARM, J. S. (University of Cincinnati, Cincinnati, Ohio 45221), \& ALLUISI, E. A. Influence of temporal uncertainty and sensory modality of signals on watchkeeping performance. Journal of Experimental Psychology, 1971, 87, 303-308. 